\title{
Ethnicity, Equality and Voice: The Ethics and Politics of Representation and Participation in Relation to Equality and Ethnicity
}

\author{
Nelarine Cornelius • Miguel Martinez Lucio • \\ Fiona Wilson • Suzanne Gagnon • Robert MacKenzie • \\ Eric Pezet
}

Published online: 25 November 2011

(C) Springer Science+Business Media B.V. 2011

\section{Work, HRM and Ethics}

The question of ethics and human resource management (HRM) has become the focus of much discussion (see, Pinnington et al. 2007). There is a growing awareness that HRM-related topics need to be considered in terms which are not purely technical or organisational, but also ethical and political. The debate is broad and has attracted a range of views and perspectives. Early initiatives by Winstanley et al. (1996) have argued that ethical perspectives must be moved to the centre of the HRM agenda. They are vital for

N. Cornelius $(\bowtie)$

School of Management, University of Bradford, Emm Lane, Bradford BD9 4JL, UK

e-mail: n.cornelius@bradford.ac.uk

M. Martinez Lucio

Manchester Business School, The University of Manchester, Booth Street West, Manchester M15 6PB, UK

F. Wilson

The Business School, University of Glasgow, Main Building, Glasgow G12 8QQ, UK

\section{S. Gagnon}

Desautels Faculty of Management, Bronfman Building, 1001 Sherbrooke Street West Montreal,

Quebec H3A 1G5, Canada

\section{R. MacKenzie}

Leeds University Business School, University of Leeds,

Maurice Keyworth Building, Leeds LS2 9JT, UK

\section{E. Pezet}

Paris Research in Norms Management and Law (Primal) and Centre d'Études et de Recherches sur les Organisations et les Stratégies (Ceros), Université de Paris Ouest Nanterre La Défense, 200, Avenue de la République,

92001 Nanterre Cedex, France

understanding the development of different perspectives and outcomes in relation to the way people are managed. Ethics is not solely the domain of an academic agenda attempting to impose some form of 'good' ethical framework from one perspective or another, but ethical issues and matters are themselves woven into the very strategic calculations and developments in the management of human resources. Ethics are of relevance to the practitioner, and they shape many discourses within HRM in terms of generic universal concerns with the notion of 'good' in economic terms, e.g. those emanating from religious legacies such as Catholic Papal declarations and Islamic views of the economy and regulated financial practices, as well as political concerns with the negative aspects of employment relations with capitalist contexts, and the corrosive effects of corruption on organisational commitment and conduct.

A series of texts have therefore outlined a range of ethical approaches and how they explain the manner in which values and virtues are framed (Fisher and Lovell 2003). Classical liberal economics, that view the importance of allowing the market to act freely so it improves the living conditions and standards of individuals, are normally contrasted with pluralist and institutionalist theories which emphasise the role of stakeholders in the firm and the importance of voice and participation. This issue of the stakeholder emerges as one of the main platforms for ensuring a more open and inclusive ethical agenda. This is mirrored in corporatist theories where the role of external agencies and the importance of regulation and long-term perspectives are privileged as corrective mechanisms for dealing with the negative features of the liberal market. In relation to HRM, Winstanley et al. (1996) have argued that ethics in the more 'inclusive' forms of HRM draw from-or should draw from-(i) basic human, civil, and 
employment rights as in the case of job security and consultation, (ii) social and organisational justice approaches that stress procedural principles of distributive justice as in systems for pay setting and performance management, (iii) universalist views based on the Kantian principles that focus on treating each individual as an end in themselves and (iv) 'community of purpose' approaches "taking a stakeholder rather than purely a shareholder view of the firm' as in cases of downsizing" (ibid: 5). In fact, Rawls' (1971) Theory of Justice draws heavily on Kantian ethics, focusing on the challenge of distributive justice as a central demand of justice as fairness.

There are competing paradigms, but an emergent and dominant view has been one that focuses on the question of stakeholders and voice. Within HRM, many observers remind us that voice and participation take many forms (Marchington and Wilkinson 2005); yet, this diversity of approaches tends to be less salient in business ethics related discussions. "The only alternative model given any credence in the literature is the stakeholder model of the organisation. Under these circumstances, it would seem that research into HRM within a stakeholder model is a necessity" (Greenwood 2002). These approaches, with their concern with the notion of the stakeholder, conform to particular visions of HRM which extol the question of voice, participation and dialogue (Kochan and Ostermann 1994-see also Martinez Lucio and Connolly for a discussion in this volume). Implicitly, these views are grounded in the position of the stakeholder as a normative ethical concern in the management of organisations (Phillips and Freeman 2003). That we need robust systems of regulation, welfare systems and formalized bodies of rights is central within such schools of thought, but the question of voice emerges as a dominant vector that runs through much of the more social and inclusive HRM debate on ethics (see Martinez Lucio 2009).

\section{HRM, Equality and Diversity}

Within HRM, the increasing interest in equality has been noted in respect to sociological and managerialist approaches. The initial forays were not indigenous to HRM or management studies, having emerged around critical feminist traditions within employment studies and a range of early studies on equal opportunities. The legal dimension has also been vital for remapping the study of work in relation to equality and the challenges brought by sexism and racism at work. One cannot outline the increasingly vast body of work on such topics-but in relation to HRM it emerged through the work of scholars in Industrial Relations, the Sociology of Work and Organisational Theory.

However, since the early 1990s, a managerial agenda has emerged that has attempted to-at best-integrate issues of equality into the management agenda within HRM and/or-at worst-has tried to contain and 'manageralise' such agendas. The focus on the business case, human capital and talent management has created a debate on the subject of managing diversity and has brought a range of criticisms that have suggested that it often ignores the role of external agents and stakeholders in ensuring more equality oriented HRM (see Greene and Kirton). Others have argued that this new management agenda marginalizes the realities and constraints in relation to such diversity initiatives (Noon 2007). A growing number of scholars that have questioned the way equality have been subsumed with a management led and business serving agenda-downplaying the role of voice, rights and stakeholder roles in ensuring the way people are to be managed and treated at work. It has been proposed that these approaches has placed diversity issues on the management agenda and explicitly challenge organisational cultural norms (Mulholland et al. 2006). However, the question of how managers can draw on differences within the workforce without also exploiting these or undermining the individuals involved is less well articulated. The argument suggests that we cannot view HRM as a series of practices that can be informed by values and ethics in such a way that they lead to particular outcomes. From an ethical perspective, these opposing perspectives may be regarded as managerial practices informed by utilitarianism on the one hand, and a more Kantian/Rawlsian rights based perspective on the other (Gagnon and Cornelius 2000). Irrespective of the ethical position, the practice-ethics nexus is complex as it is contingent on organisational politics, the structure of representation, the pattern of regulation and the overall nature and structure of voice (see Martinez Lucio and Connolly, this volume).

Further, Cipijus argues, in this volume, that we are dealing with highly static categories in the study of HRM and related fields such as Industrial Relations. Consequently, and unfortunately, we are therefore left in a debate where voice is seen in binary terms as either existing or not in any organisational context, of being autonomous or not of management designs and agendas, or being effective or not in relation to outcomes.

However, voice within the equality debate-both within the diversity and equality dimensions of that debate-rests on a meta-ethical view of voice and participation prior to looking at how these are structured. This means that we need to contextualize voice and its development. Healy et al. (2004) have in their application of the concept of intersectionality - through the study of black, female and working class trade union activists-begun to illustrate how constituencies at work draw on different areas of their existence and experiences in developing their collective identities and roles-including their voice mechanisms- 
within workplace politics. Kirton and Greene (2010) also feel that different management tiers of control and different workplace actors have to be integrated as actors and stakeholders in any attempt to open the discussion on the question of equality and diversity. Hence, the emphasis on formal/'legitimate' structures means that the existing dualism of the 'ethical' in terms of 'equality of opportunity' and 'managerialist' diversity management (ethically, Kantian/Rawlsian vs. Utilitarian approaches) continues to be the main focus. The organisational and social spaces that diversity and equality issues occupy are not captured adequately (if at all) within current discourses and methodology. So broadening the scope of that space is a vital step in any study of ethics, HRM and equality because it begins to pry the sealed and rusty door of 'voice' open. It is this that has driven the concerns of the editors of this special edition.

Our call for papers attempted to focus attention on the dilemma of how the equality debate in HRM appeared to be rhetorical in relation to voice related issues in a manner which did not underpin the effective development of equality related management and representation. Building on insights within the critical HRM approach, the call in this special edition attempted to elaborate on questions of voice and representation at various levels and within various spaces of representation. It drew on a wider pool of debates and discussions regarding equality within employment studies. The aim has been to locate the current debate on diversity and inclusion within organisations in terms of the challenge this brings to management and stakeholders in terms of its organisational values, political views and ethical orientations. The challenge is to highlight whether ethical developments synchronize and synergize with the challenge of representation and rights within the new employment context (e.g. changes in ethnic and faithbased composition). Part of the problem is that the debates on ethics are rarely focused or considered in terms of the management of ethnicity and race related issues: the link is normally implicit. What is more, the record on business ethics within many organisations is still very poor, suggesting that the ethical is related in the main to the fabrication of 'positive' corporate identity or communications management as opposed to any systematic attempt to ethically underpin the behaviour and regulation of an organisation in terms of issues such as the treatment of ethnic minorities, for example. Although articles have been written on ethnicity and ethics, these tend to be from the perspective of cross-cultural studies, without there being any social justice perspective. Issues of organisational consistency and empowerment are rarely discussed. Hence, the purpose of the special edition is to provide a forum for discussion in terms of the general link between questions of organisational ethics and questions of equality and ethnicity, the nature of the organisational and strategic links between CSR and ethical values related to equality and diversity, and the general politics of ethics and equality agendas within organisations and how competing voices (for example, unions, community networks) strive to articulate and develop alternative perspectives.

Questions of representation necessitate a discussion across different levels in terms of traditional stakeholders such as trade unions and management, new forms of representation and labour market intermediaries such as employment agencies and social enterprises, the structure of multinational corporations and their employment policies, and even the way Western management paradigms clash with competing national agendas and cultures in relation to change. We need to map the formal dimension, the broader informal dimensions, the relations of firms that cross-national boundaries and ethnic spaces, and even the representation of competing visions of representation and national culture. Hence, this special edition raises this question of representation and voice in a dynamic context.

\section{Levels and Complexity Within Equality}

The contributions begin with a set of papers that begin to challenge the way the structure of voice is understood and how key concepts within industrial relations research on migration and mobility are conceptualized. Ciupijus argues that we need to locate the discussion in terms of the historical context and examines how institutional labour market actors respond to the ethical dilemmas created by temporary labour migration. It argues that temporary labour migration interlocks the state, employers and trade unions into a highly ethically contentious system. The paper demonstrates the ways in which labour market institutions have been involved in developing ethical rationalisations vis-à-vis the moral ambiguities of temporary labour migration. These rationalisations can sustain one another: for example, the state and employers can be equally supportive of the continuation of the economically viable temporary labour migration schemes targeting highly skilled workers. Such positions tend to align economic imperatives (e.g. the skills shortages in the local labour market) with moral rationalisations (e.g. the argument of the mutual gain for temporary migrant workers and receiving societies). However, in the EU for example, the ethically charged narratives can clash: employers justifying the use of temporary migrant labour as the realisation of the pan-European freedom of movement, trade unions, on their side, employing the language of ethics in order to protect the pay and conditions of their members.

This is an issue that is central to the paper by Martinez Lucio and Connelly, but in terms of the internal organisational dynamics of equality and issues of research 
methodology. HRM and industrial relations scholars are increasingly aware of the comparative turn in the study of trade unions and immigration due to the contribution this is making in challenging the insular nature of how we view systems of regulation and their national contexts. There is now a tendency to try to map the different dimensions of industrial relations processes generally and in relation to immigration issues which, hopefully, will play a more integral part in the discussion on trade unions and immigration, moving it towards a more sensitive understanding of regulation. The move to an awareness of diversity and equality issues brings new challenges to the way we research and the way we write within the academy. They argue that for this reason we need to sustain a stronger commitment to what Greenwood (2002) calls a stakeholder view of ethics in HRM and IR based on realising the multiplicity of voices and views. It is not solely a case of 'making' traditional organisations and institutions who deal with regulation sensitive to these debates-and evaluating whether they are not—but of broadening our views of the academic and political spaces around them. The ethical implications are therefore broader than the standard discussions on inclusion/exclusion or equality/diversity in terms of 'stakeholder' views.

Social intermediaries are a major feature of the debate on equality and the labour market. MacKenzie and Forde's contribution on employment agencies illustrates the problematic aspects of such organisations due to their lack of ethical engagement and good employment practices. They study the potential and increasing role of social enterprise employment intermediaries as a means for meeting the needs of migrants. As an alternative labour market intermediary, the case study evidence reveals how social enterprise employment agencies can link people to jobs that are more appropriate to their skills and experience. Whilst the focus of private agencies is typically on the first transition of migrant workers into the labour market, social enterprise agencies can focus on subsequent opportunities for movement within the labour market. Traditionally, such moves have been facilitated through informal community based networks or familial ties. Social enterprise agencies offer one route through which such transitions for migrant workers can be formalized, as a means of preventing the perpetuation of skill under-utilisation and exploitation.

The question of institutional intermediaries and new forms of agents therefore becomes a vital aspect of the discussion on equality and voice, yet how this has evolved is an issue in terms of how it has been framed. In the paper by Wallace and Cornelius on social enterprise, the question of voice is extended into the third sector and social/community dimension of the equality debate. Their findings suggest that white British and BME TSOs do not differ in their ethicality, or in the impact of their provision on quality of life. Beneficence occupies a central role in the achievement of quality of life. Thus, it would suggest that the core values of the organisation are as important to the provision of services as its governance structures, mission and vision. For BME TSOs, the ethical reasoning and associated structures that underpin their social provision operate in a manner that mirrors that of the white British third sector. They regard this as an important finding, as it provides an alternative story to the implicit and problematic view among some that BME TSOs are less viable and well run than their white TSO counterparts.

However, within the issues of ethics, equality and organisations, there is an implicit issue regarding culture and transnational dimensions within organisations and even between national systems. This opens up a new set of issues that this special edition begins to address. The paper by Millar and Choi analyses MNCs, worker identity and the liability of foreignness caused by over-reliance on expatriate managers and under-reliance on local managers. Worker identity and the social exclusion of local managers can be a fundamental constraint on successful knowledge transfer in multinational enterprises. They show how this in turn requires an ethical stance which includes greater appreciation of "worker identity" not just in the sense of blue collar worker, but of managers who are part of the local community. Fundamental to this is the development of an adjusted identity that bridges the local and international identities, allows a greater appreciation of the local manager's identities, and the local manager's position and status - which is often intimately, bound up with his/her relationship with community and other institutions. Thus, this paper emphasised the local manager's knowledge, community and social capital. Hence questions of participation need to engage with issues of capacity building in ethical terms and a broader view of the location and relations of management and workers within an MNC.

This comparative context within questions of identity is not just bound by organisational spaces but requires a discussion of national cultures and views of the stakeholder and ethics. Fotalki and Jingjit address the question of neoliberal and 'Western' management developments in terms of Thai public sector contexts: the relevance of this is that questions of identity and participation relate not solely to the workplace and management-worker relations but have a broader dimension in terms of how they are configured in national management systems and ideologies. They question the current vogue of reiterating the message that transplanting management innovations is neither value-free nor universally applicable-otherwise the imported practices can be transformed into a hybrid, to be transferred without substance and intended effect or to promote practices of corruption that contradict the stated objectives of the pro-market reforms as Chan and Chow (2007) 
demonstrate in their longitudinal research of bureaucracy in Western China. Therefore, as the authors suggest, it may be more productive to focus on clarifying the logic of administrative reform by highlighting what preciselyrhetoric apart-the primary goals are and what interventions are needed to achieve those goals. They argue that it is even more important to design policies that are compatible with institutional frameworks and the tacit and deeply entrenched values of each cultural area-and this has significant ethical implications as we need to view questions of participation and voice in terms of cultural values and differences, and alternative ethical positions beyond the marketising rhetoric of neo-liberal perspectives.

There is, therefore, a need to appreciate that ethics and diversity work related issues are complex and broad. We need to configure approaches that look closely at how traditional actors, in terms of their structures and strategies, are related to questions of equality and how they adapt to them. The debate needs to focus on a new set of social movement actors and economic agents who influence the social and economic existence of migrants and ethnic minorities, for example, and how these latter groups engage with such spaces. Finally, the question of multinational spaces needs to be understood in terms of how corporations manage ethnicity and equality issues and how national differences need to be explained in terms of competing managerial discourses. The question of equality is therefore a point of disturbance in the arrangement of the institutional politics and processes at the organisational, social and transnational level in relation to voice.

\section{Emerging Ethical Challenges for HRM}

The special edition raises a series of analytical and ethical challenges. Once we decide to broaden the space of equality in terms of actors and institutions within a discussion on HRM, we are forced into a systematic review of how equality is regulated and at what level. This means that as well as institutionally stretching our reference points and conceptualisation of stakeholders, we need to also begin a discussion on the very principles which can underpin an open, universalist and stakeholder approach that is sensitive to the impact of globalisation, decentralisation and cross-border activity. The need to find universal principles and frameworks is the challenge. The temptation would be to fall into a position based on relativism and 'soft thinking'. Just as there are many actors and levels, there are different views and general positions on equality. That takes us part of the way to enveloping the broader spaces of equality strategies with a more flexible understanding of the concepts. It answers a long held concern that the ethical positions within management theory need to account for the role and presence of local traditions in relation to the proper treatment of individuals (Vance and Paderon 1993). Otherwise, we impose a liberal democratic perspective of equality and democracy on these broader spaces in organisational and spatial terms (MacPherson 1965).

Yet, how do we find fixity and points of reference that can sustain a broader view of how equality is regulated and managed? The temptation is to assume that the management of diversity approach, which supposedly applauds 'difference', will only do so as long as it supports the economic interests of the firm. Such approaches can resolve the dilemma of finding a series of values to underpin equality related management by referring to the positive outcomes of a range of social and organisational actions that derive from ethical approaches to HRM. Yet this approach resolves the challenge on the basis of specific outcomes but in the case of the remit of this edition we need to note that one way to resolve this ethical dilemma of how to underpin a multi-dimensional view of stakeholder voice and openness in the way we view individuals - or to partly resolve it -is to seek an extension of the democratic logic based on a vision of partnership and governance-a broadening of the role of the governance and the role of citizenship in pursuing different institutional arrangements (Chambers and Kopstein 2001). Mansbridge's (2003) work on election related issues has been seen as relevant for a plural and deliberately oriented approach to citizenship which seeks to underpin a view of representative stakeholders that may not emerge from static or district based approaches. The centrality of outsider activism is therefore important (Saward 2001). In effect, awkwardness, indeterminacy and conflict may-or must-become part of the remit of equality politics. This is one response to the challenge of understanding and forging principles that can underpin the new complexity and reality of equality and diversity.

The static and hierarchical visions and ethics of the management of diversity discourse sit unevenly with this approach because of the need to draw from the radical and critical HRM literature and not just that debate focused on the reproduction of minimal notions of rights and 'visible' equality generally.

Yet whilst we need to be cautious of the diversity management agenda in its managerialist guise-due to the minimal concern with notions of stakeholders and voicewe also have to realise that the critical and radical approaches must broaden their approach and remit. The alternative, more political engagement with equality and diversity issues has, in our view, created static characterization and categorizations which create a fixed logic which struggles to reflect more complex and nuanced developments in contemporary labour markets and organisations. Indeed, the binary nature of the debate can close 
discussion in terms of convenient differences in terms of participation and rights. Ultimately, the papers in this edition lead to a question of participation - an area with a wide variety of direct and indirect practices (Marchington and Wilkinson 2005). This debate may appear to be curiously disconnected from the mainstream of HRM and IR debates-even their radical dimensions in relation to the workplace and employment relations more generally (Martínez Lucio 2010). Yet, opening the discussion on the question of equality and stakeholders exposes us to questions of management and control and, with that, a need to comprehend regulation, self-regulation, and social innovation. So far, the debate is locked in terms of seeking the solution within the institutional traditions of management and static institutional thinking. This special edition attempts to view such challenges in terms of a range of established and new organisational actors and contexts.

Future debates will also have to envelop a broader view of voice with a relevant view of rights. The implicit view of the managerialist diversity position is that it is utilitarian (and welfare utilitarian) at best; it views equality and representation as good 'for business', not as 'good' acts in their own right. Marxist, Feminist and Post-colonial thinking have highlighted the limitations of these positions; the limits of utilitarianism are obvious (a focus on the greatest good for the greatest number means that minority interests may be neglected). It may be that we need to view radical visions of the subject and participation as a possible counter to such perspectives. We need to ground broader visions and realities of voice in terms of rights, fairness and capacity. This is clearly a problem even in the work of Rawls (1971) where the 'veil of ignorance' as a precursor for a greater appreciation of injustice and desire for equal distribution ignores minority, ethnic and non-material differences in society caused by social relations. One way to proceed may be based on a capabilities approach where the foundations and capacity for voice and participation are discussed (Alkire 2002; Sen 1992). Other approaches need to be integrated into the discussion as well: the very nature of employment relations and their implicit hierarchies need to be engaged with if the resources for voice are to be comprehended and addressed. The next step involves focusing more closely on the preconditions for a radical democratic imaginary, and not just contrasting weak and strong notions of 'voice' and concerns with its importance or not.

What the collection of papers in this special edition highlights is the limits of the ethical (and thus philosophical) presuppositions that have underpinned current conceptualisations of equality and diversity, and this in turn has influenced our understanding of what comprises voice and importantly, agency. The narratives that have emerged from the papers bring into sharp focus the limitations of the current debates, and the extent to which they limit what we 'see' as the 'legitimate' diversity agenda. Debates on participation and equality need to 'stretch' their viewssomething this edition attempts to do-but they also need to underpin them.

\section{References}

Alkire, S. (2002). Valuing freedoms: Sen's capability approach and poverty reduction. Oxford: Oxford University Press.

Chambers, S., \& Kopstein, J. (2001). Bad civil society. Political Theory, 29, 837-865.

Chan, H. S., \& Chow, K. W. (2007). Public management policy and practice in Western China: Metapolicy, tacit knowledge and implications for management innovation transfer. American Review of Public Administration, 37, 479-498.

Fisher, C., \& Lovell, A. (2003). Business ethics and values. London: Prentice Hall.

Gagnon, S., \& Cornelius, N. (2000). Re-examining workplace inequality: A capabilities approach. Human Resource Management Journal, 10, 68-87.

Greenwood, M. R. (2002). Ethics and HRM: A review and conceptual analysis. Journal of Business Ethics, 36, 261-271.

Healy, G., Bradley, H., \& Mukherjee, N. (2004). Individualism and collectivism revisited: A study of black and minority ethnic women. Industrial Relations Journal, 35(5), 451-466.

Kirton, G., \& Greene, A. M. (2010). The dynamics of managing diversity: A critical approach. London: Elsevier.

Kochan, T., \& Ostermann, P. (1994). The mutual gains enterprise. Boston: Harvard University Press.

MacPherson, C. B. (1965). The real world of democracy. London: Oxford University Press.

Mansbridge, J. J. (2003). Rethinking representation. American Economic Review, 97, 515-528.

Marchington, M. P., \& Wilkinson, A. (2005). Participation and involvement. In S. Bach (Ed.), HRM in transition. Oxford: Blackwell.

Martinez Lucio, M. (2009). The organisation of human resource strategies: Narratives and power in understanding labour management in a context of fragmentation. In S. R. Clegg, \& C. L. Cooper (Eds.), The SAGE handbook of organisational behavior (Vol 2). London: Sage.

Martínez Lucio, M. (2010). Labour process and Marxist perspectives on employee representation. In A. Wilkinson, P. J. Gollan, M. Marchington, \& D. Lewin (Eds.), The Oxford handbook of participation in organisations. Oxford: Oxford University Press.

Mulholland, G., Ozbilgin, M., \& Worman, D. (2006). Managing diversity: Words into action. London: Chartered Institute of Personnel and Development.

Noon, M. (2007). The fatal flaws of diversity and the business case for ethnic minorities. Work Employment \& Society, 21, 773-784.

Phillips, R., \& Freeman, E. (2003). Stakeholder theory and organizational ethics. San Francisco: Berrett-Koehler.

Pinnington, A., Macklin, R., \& Campbell, T. (2007). Human resource management: Ethics and employment. Oxford: Oxford University Press.

Rawls, J. (1971). A theory of justice. Cambridge, MA: Belknap Press of Harvard University Press.

Saward, M. (2001). Making democratic elections: Political equality, deliberation and direct democracy. Acta Politica, 36, 361-379.

Sen, A. (1992). Inequality reexamined. Cambridge, Massachusetts: Harvard University Press. 
Vance, C. M., \& Paderon, E. S. (1993) An ethical argument for host country workforce training and development in the expatriate management assignment. Journal of Business Ethics, 12, 635-641.
Winstanley, D., Woodall, J., \& Heery, E. (1996). Business ethics and human resource management: Themes and issues. Personnel Review, 25(6), 5-12. 